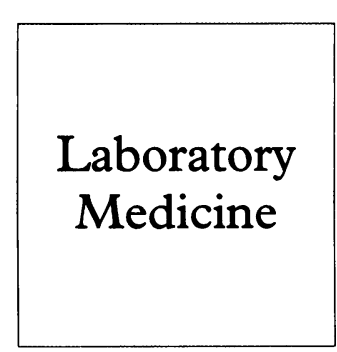

\title{
Urethral lymphocyte isolation in non-gonococcal urethritis
}

\author{
M Shahmanesh, P G Pandit, Rachel Round
}

\begin{abstract}
Aims: A pilot feasibility study to investigate the local immune response in patients with nongonococcal urethritis (NGU).

Methods: Urethral lymphocytes were extracted from first void urine (FVU) of patients with non-gonococcal urethritis and gonorrhoea using magnetic beads coated with antibody against either the pan-T cell marker CD2 or to CD4. The CD2+ and CD4+ lymphocyte content of FVU were compared between chlamydia-positive and chlamydia-negative and between first and subsequent attacks of NGU.

Results: Median CD2+ lymphocyte content of FVU was significantly higher in cases of gonorrhoea and chlamydia-positive urethritis than in chlamydia-negative NGU. Median CD2+ lymphocyte content of FVU in chlamydia-negative NGU was $15.6 \times 10^{4},(\mathrm{n}=14$ range $3 \cdot 2-111)$ which was significantly lower than in chlamydia positive NGU $\left(35.2 \times 10^{4}, \mathrm{n}=18\right.$, range $7 \cdot 4-390 \mathrm{p}=0.037)$ and gonorrhoea $\left(67 \cdot 7 \times 10^{4}, \mathrm{n}=8\right.$ range $\left.13-501, \mathrm{p}=0 \cdot 019\right)$. Comparing the first with subsequent attacks of NGU, CD2 + cell numbers were greater in those presenting with their first episode of chlamydia-negative NGU $\left(21.8 \times 10^{4}\right.$, range 5.6-111) compared with those who had experienced NGU before $\left(12.3 \times 10^{4}\right.$, range $\left.3.2-20 \cdot 4, p=0.033\right)$, but not in those presenting with chlamydia-positive NGU. There was no difference in CD4+ cells between any of the groups.

Conclusion: The lower total lymphocyte content of subsequent attacks of chlamydia-negative NGU compared with the first attack chlamydia-positive and negative NGU suggests that a different aetiology may be operating in some of these patients. Sufficient lymphocytes can be isolated from the urethra in patients with NGU for studies of lymphocyte subsets to be carried out. (Genitourin Med 1996;72:362-364)
\end{abstract}

Keywords: non-gonococcal urethritis; lymphocytes; Chlamydia trachomatis

\section{Introduction}

Chlamydia trachomatis is isolated from the urethra in $30-60 \%$ of men presenting for the first time with non-gonococcal urethritis (NGU), but less frequently in subsequent attacks. ${ }^{1}$ While other organisms have been implicated in the pathogenesis of some cases of chlamydia-negative NGU, ${ }^{2}$ the nature of the inflammatory process in the majority of these remains unknown. It has been suggested that in some of these, by analogy with the sterile urethritis observed in some cases of reactive arthritis, the inflammation may mediate through an immunological mechanism involving cross reaction with chlamydial antigens. ${ }^{3}$ Cell mediated immunological responses play an important role in the clearance of chlamydial infection ${ }^{4}$ in the eye and in animal studies. ${ }^{5}$ The same process may be operating in the urethra. A more detailed study of the local inflammatory response in the urethra requires isolation of inflammatory cells, including lymphocyte subsets from the urethral exudate. The present study investigated whether sufficient total lymphocytes are available for more detailed subset analysis and $\mathrm{CD} 4$ positive $(\mathrm{CD} 4+)$ lymphocytes for proliferative studies against potential microbial antigens encountered in the urethra. We have used antibodylabelled magnetic beads (Dynabeads) to extract lymphocytes from first void urine (FVU) of patients with urethritis. The total and CD4+ lymphocyte content of urethral exudate was compared between chlamydia- positive and chlamydia-negative urethritis and patients presenting with their first known episode of urethritis compared with those with a subsequent urethritis. The study aimed to show that sufficient number of total lymphocytes are available for more detailed subset analysis and of CD4+ lymphocytes for proliferative studies against potential microbial antigens encountered in the urethra. A small number of patients with gonococcal urethritis were also studied for comparison.

\section{Methods}

The subjects were men attending the Department of Genitourinary Medicine with a history of urethral discharge and/or dysuria. After routine history and physical examination, a plastic loop was introduced $1 \cdot 5-2 \mathrm{~cm}$ into the urethra for Gram stain film and culture for Neisseria gonorrhoeae. A diagnosis of NGU was made if the urethral smear was found to have more than 10 polymorphonuclear cells per oil immersion field (X1000) on Gram stain. A second cotton tipped wire swab was inserted 3-5 cm into the urethra for $C \mathrm{tra}$ chomatis culture. The first $5 \mathrm{ml}$ of urine was obtained by asking the patient to void urine into a $30 \mathrm{ml}$ sterile universal container holding $22.5 \mathrm{ml}$ phosphate buffered saline with $0.1 \%$ Bovine Serum Albumin (PBSA) and $2.5 \mathrm{ml}$ dithiotriatol (Sputazol, Unipath UK). The remainder of the urine was voided into a glass for routine testing. The dose of Sputazol used
M Shahmanesh

P G Pandit

Address correspondence to: Dr M Shahmanesh.

Accepted for publication 4 July 1996 
Table 1 Median number of CD2+ and CD4+ cells extracted in patients with urethritis of various microbial aetiology. Statistics by Mann-Whitney test

\begin{tabular}{|c|c|c|c|}
\hline & $n$ & $\begin{array}{l}C D 2+\times 10^{4} \\
\text { (range) }\end{array}$ & $\begin{array}{l}C D 4+\times 10^{4} \\
\text { (range) }\end{array}$ \\
\hline Chlamydia-positive NGU & 18 & $\begin{array}{l}35 \cdot 2^{\star} \\
(7 \cdot 4-390)\end{array}$ & $\begin{array}{l}13 \cdot 7(n=16) \\
(1 \cdot 2-175)\end{array}$ \\
\hline Chlamydia-negative NGU & 14 & $\begin{array}{l}15 \cdot 6 \\
(3 \cdot 2-111)\end{array}$ & $\begin{array}{l}8 \cdot 6 \\
1 \cdot 1-82 \cdot 5)\end{array}$ \\
\hline Gonorrhoea & 8 & $\begin{array}{l}65 \cdot 7 \dagger \\
(13-501)\end{array}$ & $\begin{array}{l}23 \cdot 4 \\
(4 \cdot 5-394)\end{array}$ \\
\hline
\end{tabular}

${ }^{\star} \mathrm{p}=0.037$ compared with chlamydia-negative NGU

$\mathrm{tp}=0.019$ compared with chlamydia-negative NGU

was the minimum found to be necessary to break up mucous. All tests were carried out in the morning.

The sample containing the first voided urine was immediately mixed and the contents divided equally into two universal containers and the volume made up to $30 \mathrm{ml}$ with PBSA. These were used for total T-lymphocyte (CD2+ a pan-T cell marker also present on some NK cells) and CD4+ lymphocyte estimation respectively.

For each assay two controls were set up. In the first (urine/sputazol control) $0.2 \mathrm{ml}$ citrated blood obtained from a normal control was added to $5 \mathrm{ml}$ urine obtained from a male member of the staff with no history of sexually transmitted infection, no known sexual exposure over the last five years and no cells in the FVU. The mixture was immediately added to $22.5 \mathrm{ml} \mathrm{PBSA}$ and $2.5 \mathrm{ml}$ sputazol in a universal container. The second control (PBSA control) consisted of $0.2 \mathrm{ml}$ citrated blood added to $30 \mathrm{ml}$ PBSA in another universal container. Both controls were divided immediately into two and treated as described above for the urethral sample. The remainder of the blood was sent for a differential leucocyte count and lymphocyte subset (CD3+ and CD4+) estimation.

The universal containers with the urethral samples and controls were spun for 5 minutes at $2,000 \mathrm{rpm}(1600 \mathrm{~g})$, the supernatant carefully decanted and the pellet washed with 25 $\mathrm{ml}$ of PBSA, spun as before and decanted. The pellets were resuspended in $1 \mathrm{ml}$ PBSA and transferred to plastic stoppered test tubes, taking care not to introduce air bubbles. Dynabeads (Dynal, UK) $(15 \mu \mathrm{l})$ coated with anti-CD2 (49 patients) antibody was added to one set of tubes containing the urethral samples and the two controls. The other set received anti-CD4 antibody (32 patients). Some patients underwent $\mathrm{CD} 2+$ or $\mathrm{CD} 4+$ assay only. The test tubes were placed on a slowly rotating roller mixer at $4^{\circ} \mathrm{C}$ for $20 \mathrm{~min}$ utes, washed three times with $5 \mathrm{ml}$ PBSA on a Magnetic Particle Concentrator (Dynal MPC6 ${ }^{\mathrm{R}}$, Dynal AS, Oslo, Norway). The Dynabeads were finally suspended in $150 \mu \mathrm{l}$ of PBSA and $50 \mu \mathrm{l}$ white blood cell counting fluid. The number of lymphocytes was counted in a

Table 2 Median (range) number of CD2+ cells $\left(\times 10^{4}\right)$ extracted from the urethra of men without a history of previous urethritis and those with one or more previous attacks. comparison of chlamydia-positive and negative groups

\begin{tabular}{lllll}
\hline & First attack & $n$ & Reinfection & $n$ \\
\hline Chlamydia-positive NGU & $35 \cdot 2(12 \cdot 8-50)$ & 8 & $44 \cdot 9(7 \cdot 4-390)$ & 9 \\
Chlamydia-negative NGU & $21 \cdot 8(5 \cdot 6-111)$ & 8 & $12 \cdot 3^{\star}(3 \cdot 2-20 \cdot 4)$ & 6 \\
\hline
\end{tabular}

${ }^{\star} \mathrm{p}=0.033$ compared with first attack.
Neubauer counting chamber. $4 \times 16$ squares were counted and the estimated number of lymphocytes per urethral exudate calculated for the whole sample by multiplying by 2000 .

Extraction was calculated for the urine/ sputazol control and the PBSA control using the total blood lymphocyte count (for the $\mathrm{CD} 2+$ ) assay and the blood CD4+ count for the CD4+ assay respectively. The lymphocyte content of the PBSA controls were used to calculate estimated actual $\mathrm{CD} 2+$ and $\mathrm{CD} 4+$ content of the urethral exudate.

Statistics was by Mann-Whitney test using a Minitab-7 program. Log transformation of the data was also used and Student's $t$ test was applied to $\log$ transformed data.

\section{Results}

Mean extraction (SD) of the urine/sputazol controls for CD2+ cells was $45(20 \cdot 7) \%$ ( $n=$ 49 , range $7-91 \cdot 6 \%$ ) and for CD $4+$ cells $43 \cdot 1$ $(22 \cdot 7) \quad(\mathrm{n}=32$, range $10-85 \cdot 9 \%)$. Mean extraction (SD) for PBSA controls for CD2+ cells lymphocytes was $61 \cdot 5 \%(17 \cdot 3) \quad(n=50$ range 27-100) and for CD4+ cells $69 \cdot 3 \%$ $(16 \cdot 9)(n=34$ range $38 \cdot 7-100)$. The differences between CD2+ and CD4+ extractions were not significant for each control. However, for both CD2+ and CD4+ cells the urine/sputazol extraction was significantly lower (Mann-Whitney $p=0.0001$ ) than the PBSA control. There was good correlation between urine/sputazol and PBSA controls in individual samples $(p=0.012)$.

The total number of CD2+ and CD4+ cells extracted in the three groups of patients is shown in table 1. FVU from patients with gonorrhoea and chlamydia-positive NGU contained a greater amount of $\mathrm{CD} 2+$ cells compared with chlamydia-negative NGU. This difference remained when data were log transformed before analysis. When corrections were made for extraction using the urine/ sputazol control, the estimated actual CD2+ cells remained greater in chlamydia-positive (median $82 \cdot 5$, range $18 \cdot 7-873$ ) than chlamydia negative (median 22.2, range 6.3-188, Mann-Whitney $p=0.008$ adjusted for ties). There was no difference between chlamydiapositive and gonorrhoea patients (median 121, range 16-2880).

CD4+ cells obtained from the urethral exudates was similar in all three groups even when corrected for extraction. There was no difference between the groups when $\mathrm{CD} 2+/ \mathrm{CD} 4+$ ratios were compared.

Patients were stratified according to those who had no previous known episode of urethritis compared with those with a history of one or more episodes of non-gonococcal urethritis (Table 2). CD2+ cell numbers were greater in those presenting with first episode of chlamydia-negative NGU compared to those who had experienced NGU before. This difference between first and subsequent attacks of urethritis was not observed in patients presenting with chlamydia-positive NGU. There was no difference in CD4+ cells between any of the groups. 


\section{Discussion}

The nature of the inflammatory process in chlamydia-negative NGU remains to be determined. Reactive arthritis secondary to gastrointestinal infections by organisms such as yersinia and salmonella is not infrequently associated with a sterile urethritis. ${ }^{6}$ Moreover, recurrence and persistence of urethritis without known sexual exposure not uncommonly occurs in men. It is becoming recognised that some of the damage caused by $C$ trachomatis in the eye $^{7}$ the Fallopian tube ${ }^{8}$ and joints ${ }^{9}$ is immunologically mediated. The damage may be partially caused by cell mediated immunity. ${ }^{7}$ It has been suggested that similar mechanisms may be operating in the urethra. ${ }^{310}$ Lomas et al ${ }^{11}$ have shown that the inflammatory stimulus in the urethra, as judged by the chemotactic stimulus to polymorphonuclear leucocytes, persists despite standard treatment, and the apparent eradication of chlamydia in those in whom the organism was isolated. They also showed that the chemotactic stimulus to polymorphonuclear leucocytes did not significantly fall after standard treatment of chlamydia-negative urethritis suggesting that, at least in some of these patients, the urethritis may either be caused by microorganisms not susceptible to the currently used standard medication for NGU, or the consequence of a non-infective inflammatory state in the urethra.

The present study shows that urethral exudate from patients with chlamydia-negative NGU contain significantly less CD2+ lymphocytes (a pan-T lymphocytic marker also present on Natural Killer cells) compared with those in whom $C$ trachomatis was isolated. A comparison between first and subsequent attacks of NGU also showed that there was a significantly lower lymphocyte content of urethral exudate in subsequent attacks of chlamydia-negative NGU compared with the first attack. These results would be compatible with the hypothesis ${ }^{310}$ that in some cases of repeated attack of NGU in which $C$ trachomatis is not isolated, a different aetiology from those with their first attack may be operating. The results should, however, be interpreted with caution as the reproducibility of the lymphocyte isolations was not tested in the present study.

Chlamydia-negative NGU is not a homogeneous entity and may contain patients with persistent or recurrent NGU following standard antimicrobial therapy and without sexual exposure. ${ }^{10}$ The magnitude of the inflammation, as judged by the number of inflammatory cells in the urethral exudate, is significantly lower in patients with persistent NGU without known sexual exposure compared to NGU following sexual exposure. ${ }^{12}$ While all the patients in the present study had unprotected sexual exposure before they presented with NGU, it is possible that some may have recurrent or persistent urethritis, and the reduced number of $T$ lymphocyte obtained in chlamydia-negative subsequent NGU may be a function of the lower inflammatory response in this condition. This is unlikely, however, since this study showed that the urethral exudates of patients with gonorrhoea, which is often frankly purulent, contain similar CD2+ content as those with first attack NGU in which the magnitude of the inflammatory response is usually less severe.

There is increasing evidence for a protective role for CD4+ and even more for CD8+ cells in the host defence against chlamydial infection. ${ }^{513}$ While the present study did not show any quantitative differences in the $\mathrm{CD} 4+$ content of urethral exudate between chlamydiapositive and negative urethritis and between the first and subsequent attacks, there may be qualitative differences in the response to some antigens. Moreover, the difference in the CD2+ content of chlamydia-negative first and subsequent attacks warrants investigation of other lymphocyte subsets. Macrophages are also involved in the clearance of $C$ trachomatis $^{14}$ and the urethral exudate in first attack NGU contain significantly more macrophages than during subsequent attacks regardless of whether $C$ trachomatis was isolated or not. ${ }^{12}$

The present study demonstrates that urethral exudate of patients with NGU contains sufficient numbers of lymphocytes for studies of the local immunological response. While the short period of contact with urine and the dithiotriatol, used to break up mucous, reduces the lymphocyte content, in the absence of dithiotriatol the lymphocytes remain viable in the majority of the samples and can be cloned (M. Brunst personal communication). Further work in characterisation of the immunological response of the urethral mucosa in NGU is warranted.

1 Alani MD, Darougar S, MacD Burns DC, Thin RN, Dunn $\mathrm{H}$. Isolation of Chlamydia trachomatis from the male urethra. Brf Venereal Dis 1977;53:88-92.

2 Woolley PD. Recent advances in non-gonococcal urethritis pathogenesis, investigation and treatment. Int $\mathcal{f} \mathrm{Sex}$ Transm Dis AIDS 1990;1:157-60.

3 Shahmanesh M. Problems with non-gonococcal urethritis. Int f STD AIDS 1994;5:390-9.

4 Bailey RL, Holland MJ, Whittle HC, Maybey DC. Subjects recovering from human occular chlamydial infection have enhanced lymphoproliferative responses to chlamydial antigens compared with those of persistently diseased conantigens compared with those of per
trols. Infect Immun 1995;63:389-92.

5 Igeteseme JU, Magee DM, Williams DM, Rank RG. Role for CD8+ cells in anti-chlamydial immunity defined by chlamydia-specific T-lymphocyte clones. Infect Immun 1994;62:5195-7.

6 Keat ACS. Does sterile urethritis occur in Reiter's syndrome secondary to gastrointestinal infection? $\mathrm{Br} \mathcal{F}$ Rheumato 1992;31:106.

7 Courtright P, Lewallen S, Howe R. Cell-mediated immunity in trachomatous scarring. Evidence from a leprosy population. Ophthalmology 1993;100:98-104.

8 Witkins SS, Jeremias J, Toth M, Ledger WL. Proliferative response to conserved epitopes of the Chlamydia trachoma$t$ is and human 60 -kilodalton heat-shock proteins by lymphocytes from women with salpingitis. Am $\mathcal{f}$ Obstet and phocytes from women with

9 Kingsley G, Sieper S. Current perspectives in reactive arthritis. Immunology Today 1993;14:387-91.

10 Munday PE. Persistent and recurrent non-gonococcal urethritis. In: Taylor Robinson D, ed. Clinical Problems in Sexually Transmitted Diseases. Dordrecht: Martunus Nijhof, 1985:15-35.

11 Lomas DA, Natin D, Stockley RA, Shahmanesh M Chemotactic activity of urethral secretions in men with urethritis and the effect of treatment. F Infect Dis 1993 167:233-6.

12 Shahmanesh $M$. Characteristics of inflammatory cells in urethral smears from men with non-gonococcal urethritis. Genitourin Med 1989;65:18-21.

13 Magee DM, Williams DM, Smith JG, Blieker CA, Grubbs BG, Schachter J, et al. Role of CD8 cells in primary Chlamydia infection. Infect Immun 1995;63:516

14 Monnickendam MA. Chlamydial genital infections In Wright DJM, ed. Chmunology genital infections. In Wright DJM, ed. Immunology of Sexually Transmitted Diseases. 